\title{
Performance Measurements in the Greening of Supply Chains
}

Maria Björklund, Uni Martinsen and Mats Abrahamsson

The self-archived postprint version of this journal article is available at Linköping University Institutional Repository (DiVA):

http:/ / urn.kb.se/ resolve?urn=urn:nbn:se:liu:diva-68842

N.B.: When citing this work, cite the original publication.

Björklund, M., Martinsen, U., Abrahamsson, M., (2012), Performance Measurements in the Greening of Supply Chains, Supply chain management, 17(1), 29-39.

https:// doi.org/ 10.1108/ 13598541211212186

Original publication available at:

https:// doi.org/ 10.1108/ 13598541211212186

Copyright: Emerald

http:// www.emeraldinsight.com/ 


\section{PERFORMANCE MEASUREMENTS IN THE GREENING OF SUPPLY CHAINS}

Björklund, M., Martinsen, U., Abrahamsson, M.

Accepted for publication in Supply Chain Management: An International Journal, and scheduled to be published in issue 1 of volume 17.

\section{ABSTRACT}

\section{Purpose}

In response to increasing demands on improved environmental performance, companies need to develop their capabilities in assessing the environmental performance of their operations. Knowledge among practitioners as well as solid research results in this area lacks. This paper aims to present a framework of dimensions important to consider regarding environmental measurement in supply chain management. The paper also aims to present a practical example on how environmental performance measurements can be a success by applying these dimensions.

\section{Design/methodology/approach}

Literature regarding logistics management and performance measurement is coupled with theories regarding environmental logistics and green supply chain management. A framework is developed. A case study based on four actors in a reverse supply chain is used to illustrate the framework.

\section{Findings}

The paper outlines important aspects to consider in the design of environmental performance measurements in supply chain management and identifies shortcomings in existing research. The case presents successful examples of how environmental performance measurements can be applied across managerial levels as well as company borders in a supply chain.

\section{Practical implications}

The literature review shows shortcomings in the measuring tools applied today. The case provides examples of how these shortcomings can be addressed.

\section{Originality/value}

This paper addresses the intersection between environmental logistics and performance measurements. The case shows how environmental performance measurements can be applied over a single company's borders by including four different actors in the supply chain.

Keywords: Environmental logistics, Logistics measurement and performance, Green performance measurement, Supply chain management. 


\section{INTRODUCTION}

In response to the increased external environmental demands, such as stricter regulations and increased customer demands, companies need to develop their capabilities in assessing, managing and controlling the environmental performance of their operations. A growing number of companies have begun developing and using environmental sustainability indicators (Veleva et al, 2003). Supply chain managers must consider the impact of their performance on the natural environment (Zhu et al., 2008; Zsidisin and Sifert, 2001). The companies' environmental performance can be very important performance drivers to measure in order to capture important information that can be used to increase the competitive advantage. The findings of Cuthbertson and Piotrowicz (2008) suggest that environmental criteria are increasingly important to develop sustainable business practices. Both researchers and practitioners that investigate supply chain measurements must remember to consider not only financial but also environmental aspects. The case study of Vasileiou and Morris (2006) shows that greater importance is now given to environmental factors both as influences on decision making and as indicators of business performances. Already in 1995, Noci (1995) described that managers in Sweden, Norway and Denmark consider improvements in environmental performance as one of the basic competitive priorities.

There is a lack of knowledge regarding how to measure environmental performance in supply chain management. The linkage between environmental activities in the supply chain and organizational performance is according to Vachon and Klassen (2008) not thoroughly examined. According to Hervani et al. (2005) green supply chain management performance measurements are virtually non-existent. These statements are further supported by the findings of Cuthbertson and Piotrowicz (2008) describing that performance measurement approaches seldom include environmental aspects. They describe guidelines for enhancement and development of environmental supply chain management performance measurement tools as one important issue to address in future research. The limited understanding of environmental management in the supply chain has also hampered the development of a widely accepted framework that would characterize and categorize environmental activities in the supply chain (Vachon and Klassen, 2008). In addition McIntyre et al. (1998a) states that there seems to be no place for the environment in future supply chain measurements, and that the environment runs the risk of being sidelined.

The need for more knowledge regarding environmental performance across different actors in the supply chain is recognised by practitioners. When communicating environmental performance to logistics service providers and shippers we have discovered a scepticism regarding the content of some environmental business offerings. One example is the use of environmental performance measurements regarding the logistics services. Both shippers and logistics service providers singled out the lack of reliable environmental measurements and measurement systems as one important area to address in future research. Environmental performance measurements adjusted to a logistics setting are needed and wanted among both logistics service providers and shippers. The demand is also rising due to the fact that environmental measurements are becoming an important part of several logistics service provider's business offering, as well as a way to differentiate the product, i.e. the logistics service, in a very competitive market. These shortcomings show a need for a systematic way to design environmental performance measurement systems regarding supply chain management. One important point of departure is to identify important dimensions that ought to be considered when measuring environmental performance in supply chain management. 
The purpose of this paper is threefold:

1. To make a synthesis of what has been published on green measuring in supply chain management and thereby assessing the state of the art in the field.

2. To analyse strengths and shortcomings in prior research within the field based on an identification of important dimensions to consider when measuring environmental performance in supply chain management.

3. To provide a practical example showing that it is possible to succeed with environmental performance measurement in supply chain management by applying the dimensions identified.

The outline for this article is as follows: In the section following this introduction, the research design for this paper will be presented, followed by a description of the case study. Next, a framework with important dimensions is presented, together with the findings from the articles. A presentation of the case structured in accordance with the dimensions in the framework follows. The paper ends with a discussion of the findings made and outlines future research needs.

\section{RESEARCH DESIGN}

Literature reviews and a case study are applied in this paper. Literature regarding logistics management principles and performance measurement are coupled with theory regarding environmental logistics. The literature review addressed purpose one and two of this paper. The third purpose is addressed with a case study. Most of the case study was performed before the literature review was conducted for the purpose of providing guidance to the company. However, the findings from the literature review and the framework developed showed that this case is a good way to illustrate how a supply chain can succeed with environmental performance measurement taking all the identified dimensions into consideration.

\subsection{Literature review}

The literature review aimed at identifying articles within the field of performance measurement and environmental logistics and supply chain management. A total number of twelve searches (see table 1) were made and 1137 articles were identified. The search terms had to be included in the title or abstract in order to get a hit.

Table 1 Number of hits in the literature review (measur* was used in all twelve searches)

\begin{tabular}{|lccc|} 
& environment* & green* & Sustainab* \\
\hline logistic* & 97 & 10 & 14 \\
\hline supply & 293 & 42 & 79 \\
transport* & 326 & 43 & 61 \\
purchas* & 131 & 20 & 21
\end{tabular}

The literature review was intentionally meant to cover a large scope of literature, in order not to miss any important articles. However, most of the 1137 articles found did not address the right subjects. Many of the articles were not about measurements or measuring, but about different measures, or actions, to take. Those hits did not fit into the predefined criteria. Regarding the term "environment”, most hits were not about the natural environment, but instead about the surrounding environment described in contingency factors etc. Regarding 
the search term supply, many of the articles dealt with energy supply, which did not fit into this study. The term transport also resulted in a large number of hits. Many of them included public transportation or transportation that does not fit into the purpose of this article, e.g. particle transport. And many of the purchasing articles dealt with consumer buying behavior and marketing, which was not considered relevant for this article. Finally a number of 17 articles were identified that fulfilled the criteria set for the literature. The articles are presented in table 2 below.

Table 2 Relevant articles found in the literature review.

\begin{tabular}{|l|l|}
\hline Author(s) & Year \\
\hline Azzone \& Noci & 1998 \\
\hline Bickel et al. & 2005 \\
\hline $\begin{array}{l}\text { Cuthbertson \& } \\
\text { Piotrowicz }\end{array}$ & 2008 \\
\hline Facanha \& Horvath & 2005 \\
\hline Gerbens-Leenes et al. & 2003 \\
\hline Hervani et al. & 2005 \\
\hline Keller et al. & 2002 \\
\hline Krikke et al. & 2003 \\
\hline Lakhal \& H'Mida & 2007 \\
\hline Lu et al. & 2007 \\
\hline Markley \& Davis & 2007 \\
\hline McIntyre et al. & $1998 a$ \\
\hline McIntyre et al. & $1998 b$ \\
\hline Vachon \& Klassen & 2007 \\
\hline Vasileiou \& Morris & 2006 \\
\hline Veleva et al. & 2003 \\
\hline Zhu et al. & 2008 \\
\hline
\end{tabular}

\subsection{Case study}

Seuring (2008) investigates case study research in sustainable supply chain management and supply chain performance management and indicates several deficiencies regarding the way case studies are presented within these two areas. Since our study lies in the borderland between these areas we find these deficiencies important to address. He points at the importance of: justifying the selection of case(s), addressing how the information was analysed as well as presenting how the rigor of the research was ensured. Furthermore, he describes the research as just approaching one stage of the supply chain and the data collection via a few interviews and an analysis of the companies' homepages. This points to the need for more in depth studies of supply chain oriented cases.

The case was selected since the companies' environmental performance measurements in supply chain management show how to overcome several of the shortcomings identified in the literature review. Furthermore, it is a case that consists of more than one actor, i.e. the four actors: retailers, wholesalers, breweries and the reverse company Returpack Svenska AB (Returpack). (For more information visit www.returpack.se)

Information has mainly been gathered by the use of semi-structured interviews with the logistics manager, environmental manager, financial manager and managing director at Returpack as well as representatives from wholesalers, breweries and retailers.

To estimate the economical and environmental impact of the changes suggested in the supply chain internal documentation regarding the system was used (costs, distances, volumes, 
storage, handling costs). Observation was also to a minor extent used to provide an understanding of the production unit.

Several researchers participated in the gathering of the data. To increase the trustworthiness of the case description, written case documentations were presented to Returpack's managing director, environmental manager, and financial manager for approval.

The estimation of the environmental impact from transports was done with the use of information provided from a Swedish independent organization, The Network for transport and the environment (NTM). One shortcoming in environmental calculations is that the use of source, method and estimations made can result in very different outcomes. However, the data available on NTM's homepage is decided in collaboration between representatives from all the different transport modes, which largely increases the trustworthiness of this data (for more information visit www.ntm.a.se). There are other ways of calculating environmental impact from transports, for example those suggested by Freight Best Practice (Freight Best Practice, 2009a\&b). However, these methods are not used in this paper.

\section{A MULTIDIMENSIONAL CLASSIFICATION FRAMEWORK}

This section is based on the literature review and addresses the first purpose of the study. In order to present the findings in an organised way we use a framework with main themes within the area of measuring, here called dimensions. One important point of departure in the identification of dimensions was a framework developed by Caplice and Sheffi (1995). However, we developed the framework further. The dimensions in the framework are summarized in table 3, where the original framework is also presented. One additional criterion used by Calplice and Sheffi (1995) was useful, which we chose to leave out because this would require judgements that are difficult to do on the information presented in the articles solely. The framework dimensions are applied in order to systematically sort the content of the 17 articles.

Table 3 Framework dimensions

$\begin{array}{ll}\text { Caplice and Sheffi (1995) } & \text { Dimensions in this article } \\ \text { Comprehensive } & \text { Stakeholder perspective } \\ \text { Causally oriented } & \text { The purpose of measuring } \\ \text { Vertically integrated } & \text { Managerial levels of measuring } \\ \text { Horizontally integrated } & \text { Measuring across the supply chain } \\ \text { Internally comparable } & \text { Combination of measurements }\end{array}$

\subsection{Stakeholder perspective}

The influence from stakeholders such as governance, customers and suppliers are often described as important driving forces and enablers in environmental performance. Caplice and Sheffi (1995) write that it is important that a well designed logistics performance measurement system captures all relevant constituencies and stakeholders of the process. They state that most measurement systems forget for example the customer perspective.

Most of the articles found in the literature have a company or supply chain focus. For example Markley and Davis (2007) focus on the company when writing about the natural resource based view of the firm (NRBV), while Cuthbertson and Piotrowicz (2008) focus on the supply chain in their study of found measurements. However, the article of Bickel et al. (2006) is different. The focus is more on society as a whole. The authors discuss the impact of transports on human health, plants and animals, building materials, agriculture and 
ecosystems. Measurements covered by the authors are used in order to reduce transport impact on these stakeholders.

Some of the authors (e.g. Lu et al., 2007 and Zhu et al., 2008) write about stricter regulations that requires more environmental focus from different actors. Accordingly, Facanha and Horvath (2005) write that environmental awareness is increasingly important to society, government and industry. Furthermore, Hervani et al. (2005) present a performance measurement system in which external stakeholders like customers, suppliers, the community, regulators and Non-Governmental Organizations (NGO's) are influencing the environmental performance indicators.

Both Lu et al. (2007) and Zhu et al. (2008) mention the increasing community and consumer pressures on companies to become more environmentally aware. Markley and Davis (2007) discuss environmental performance affecting both customer and employee satisfaction. Furthermore, Cuthbertson and Piotrowicz (2008) found some measurements linked to the customers in their research. However, they thought there was a lower level than expected of these measures. Moreover, Zhu et al. (2008) write about green supply chain management as a means to achieve corporate profit and market shares. Market shares are closely related to customers, as well as corporate profit. The latter is also of interest for shareholders.

Lu et al. (2007) write about measuring supplier's performances in order to evaluate the suppliers based on their environmental performance. This seems to be done merely from the company's point of view, and the supplier interests don't seem to be considered in the measuring.

\subsection{The purpose of measuring}

There are many reasons as to why organisations measure their performance. Some examples presented in the literature are to see progress, identify success, report performance, evaluate performance, confirm what they already know, reveal what they do not know, understand their processes, assist operational personnel, identify problems and bottlenecks, form new objectives and targets, determining future courses of action and to confirm priorities. (Gunnasekaran et al. 2004 and 2007; Holmberg, 2000ab; Neely, 1998).

Caplice and Sheffi (1995) describe the importance of the logistics measurement system tracking activities and indicators that influence both future as well as current performance. They state that financial metrics are lagging indicators with an internal focus while nonfinancial measures tend to indicate future performance. Depending on the purpose of the performance measuring the time focus can be on historical (e.g. see progress, report and evaluate performance), present (e.g. assist operational personnel) or future performance (e.g. form new objectives and targets, determining future courses of action and confirm priorities).

One article found in the literature review states that defining the overall goal(s) of the system measured ought to be the point of departure in any performance measurement system within green supply chain management (Hervani et al. 2005). The literature provides several examples of purposes with regard to performance measurement. For example, several reasons for measuring supply chain performance are identified in a literature review conducted by Cuthbertson and Piotrowicz (2008), such as increasing the understanding, collaboration and integration between supply chain members. Measuring can also help an organisation target the most profitable market segments or identify a suitable service definition.

According to Hervani et al. (2005) the basic purpose of performance measurement in green supply chain management is external reporting, internal control (managing the business better), and internal analysis (understanding the business better and continuous improvement). 
Performance measurement can also have other purposes such as to determine the efficiency and effectiveness of an existing system or to compare competing alternative systems, as well as being an important "support" in the planning, design, implementation and monitoring of systems. Zhu et al. (2008) describe similar purposes with performance measurement as they state that practitioners can use different forms of scales to measure green supply chain management for continuous improvements, implementation of green supply chain management, and benchmarking.

Bickel et al. (2006) presents a totally different purpose for their measuring as they take a societal perspective regarding the negative environmental impact from transport. Their purpose is to be able to quantify the external costs of transportation.

The literature review by McIntyre and Smith (1998b) describes the criticism by several authors regarding the focus of the measures. There seems to have been a large focus on measuring the present effects of historical decisions instead of measuring in order to provide support for the present and future management. The time views in focus are described as being too short and having too large a focus on reducing costs and time.

The measurement system proposed by Lu et al. (2007) aims at monitoring, measuring progress and evaluating the environmental status of potential suppliers. The measures suggested (such as percentage of suppliers having an EMS and environmental report or the reusability of materials used and how easily the product can be disassembled) do however indicate that the measures capture the present situation and not on the future environmental potentials of the different suppliers.

According to Hervani et al. (2005) the time focus in environmental measures (i.e. historical, present or future) is dependent on the organisation's evolutionary stage in environmental management. Reactive organisations focus on complying with new laws while proactive organisations not only measure compliance with new laws but measures also in order to gain information to green the business and develop in a more green direction.

\subsection{Managerial levels of measuring}

According to Caplice and Sheffi (1995) it is of large importance that the logistics measurement system is vertically integrated, i.e. that the measurement system translates the overall firm strategy to all decision makers within the organisation. They argue that the measurement system ought to be linked to decisions of all managerial levels; strategic, tactical as well as operational.

Several researchers describe the key characteristics of management decisions taken on the three managerial levels. Strategic level measures influence top management decisions. Changes on this level are characterised by long time horizons and cover infrastructure planning, such as additional facilities, locations and make/buy decisions. Tactical decisions are taken by middle level management and include for example capacity planning and utilisation of the equipment. Finally operational decisions made by lower level management address matters such as scheduling and routing. Authors point to the importance of vertical integration describing the tactical plan as a key input for the operational plan (Vanteddu et al., 2006; Gunasekaran et al., 2004).

McKinnon (2003) describes managerial levels in his decision framework describing how decisions on different levels influence the environmental impact of freight transport operations. The levels are: (1) Logistics physical structures (numbers, locations, and capacity of factories, warehouses, shops and terminals); (2) Pattern of trading links (selection of suppliers, distributors and customers); (3) Scheduling of production and distribution (translate 
trading links into discrete freight flows); and (4) Management of transport resources (choice, routing and loading of vehicle). Aronsson and Huge Brodin (2006) have further developed this framework, showing that decisions at different levels both create opportunities and set limitations for decisions made on other levels, and thereby pointing out the importance of vertical integration. Decisions made at a higher structural level set limitations and provide opportunities for lower levels.

Several of the literature sources point at the importance of linking environmental performance measurement to strategy, and environmental performance is also described as providing a strategic advantage (Markley and Davis, 2007).

Hervani et al. (2005) state that measures are best developed with derivation from and links to corporate strategy and that the performance measurement for green supply chain management (GSCM/PM) must fit within the strategy of the supply chain. Furthermore they write that measures should be present at multiple levels and they present a wide variety of measures; fugitive non-point air emissions, spill and leak prevention, total energy use and total fuel use. The authors state that these measures have implications for all managerial levels (strategic, tactic and operational). Both strategic and operational personnel play important roles in the environmental performance measurement. Top management must provide financial and strategic support for environmental performance measurement, while operational personnel must be involved in training and data acquisition to effectively implement the measurement system.

Also McIntyre and Smith (1998b) describe the importance of environmental performance metrics being strategic in orientation. However, their study shows that companies seldom incorporate strategic implications of environmental performance. Furthermore, they did not identify any literature describing how companies' environmental management strategies have been integrated in the management decision-making.

\subsection{Measuring across the supply chain}

Caplice and Sheffi (1995) describe the importance of horizontally integrated performance measurement systems, i.e. that the measurement system includes all pertinent activities, functions, and departments along the process and that they encourage integrating operations along the entire supply chain. They stress the importance of applying process oriented measurements.

Fabbe-Costes and Jahre (2008) carry out a literature review aiming at investigating the number of organisations or participants in the "integrated supply chain". The categories applied by them span from limited dyadics (integration between focal company and its supplier or customer) via limited triadic (integrations of suppliers- focal company- customers) and extended supply chains. Their findings show that even if many of the papers reviewed discuss the importance of an extended scope only a small extent actually present measurements that do so.

Most of the articles found in the literature review write about measuring environmental performance in supply chains. Vachon and Klassen (2008) have studied the effect environmental collaboration in supply chains has on manufacturing and environmental performance by measuring environmental cooperation between companies and their suppliers and customers. Veleva et al. (2003) suggest that many companies' major environmental impact is not at their own plants. Rather, they are found in the supply chain or in product use or disposal. So, in order to measure the overall environmental impact of a company, there is a need to consider the supply chain of the company. Lakhal and H'Mida (2007) analyses the 
structure of the supply chain in a Canadian petroleum refinery company, from supplier to client, and studies actual contaminants through the supply chain.

Even though the research of Cuthbertson and Piotrowicz (2008) has its starting point in the supply chain, the authors found a lack of supply chain focus in their empirical data containing fifty documented cases. Most of the cases focused on internal issues at company level, often measuring the performance of functions, instead of on the whole supply chain. Also, the authors came to the conclusion that environmental aspects often were ignored when measuring supply chains.

Most studies measure single internal functions or activities instead of measuring across the supply chain. Vasileiou and Morris (2006) state that issues of sustainability have tended to concentrate on a particular stage of the supply chain, rather than on the supply chain as a whole. Furthermore, in the literature review conducted by McIntyre et al. (1998b), the authors found that certain discrete elements of the supply chain have been environmentally developed, but writes that a risk arises when viewing any of the aspects in isolation.

Even though many authors promote measuring environmental performance in supply chains (e.g. Veleva et al. 2003; Hervani et al., 2005; Markley and Davis, 2007), there is also recognition in the difficulty in doing just that. Veleva et al. (2003) point out the difficulty of measuring environmental impact caused by the supply chain, because of the issue of data availability. Hervani et al. (2005) also stress the complexity of including customer/supplier input when measuring across organizational boundaries. Nonetheless, Facanha and Horvath (2005) write that Life Cycle Analysis (LCA) is a well-established approach when assessing environmental impacts of supply chains. The data collected when using LCA can be used to reengineer supply chains in order to improve their environmental performance. The authors use LCA to establish whether outsourcing of logistics functions or keeping the functions inhouse have the most environmental impact. Thus, the authors measure environmental performance across company borders.

Cuthbertson and Piotrowicz (2008) fit measures into the process perspective or the function perspective. No environmentally related measurements seem to belong to the process perspective, while some function measurements are of interest in the environmental measurement. Process oriented measurements are of importance in order to measure the environmental impact from a supply chain perspective.

\subsection{Combination of measurements}

According to Caplice and Sheffi (1995) it is important that measurements are internally comparable, i.e. that they recognize and allow for trade-offs between the different aspects of performance. Both practitioners and researchers realise the importance of financial and nonfinancial performance measures, however most companies have failed to represent them in a balanced framework (Gunasekaran et al., 2004). It is important that the performance measurements applied not only focus on financial aspects of a firm since this can make the firm adopt a skewed approach that does not fully support the overall supply chain objectives (Vanteddu et al., 2006). Keller et al. (2002) shows an increased use of multi item scales in the research published in the leading logistics journals. However, Holmberg (2000b) state that the measurements applied in the performance measurement systems often is too isolated and incompatible.

Several of the articles present environmental measurements that can be grouped together into measurement systems. Some of the most frequently reoccurring environmental measurements in the articles studied are: air emissions (e.g. Hervani et al., 2005; Bickel et al., 2006; Veleva et al., 2007; Azzone \& Noci, 1998), energy use (e.g. Hervani et al., 2005; Zhu et al., 2008; 
Veleva et al., 2003; Azzone \& Noci, 1998; Gerbens-Leenes et al., 2003), recycling (e.g. Lu et al, 2007; Veleva et al., 2003), fuel use (e.g. Cuthbertson \& Piotrowicz, 2008) and water use (e.g. Hervani et al., 2005; Azzone \& Noci, 1998; Gerbens-Leenes et al., 2003).

McIntyre et al. (1998b) bring up examples where companies are constructing environmental performance methodologies that support the existing logistics performance measurements. However, Vasileiou and Morris (2006) show in their research that economic factors tend to be prioritized over environmental and social, although there is a clear interdependency between these factors. Nonetheless, Facanha and Horvath (2005) use economic, environmental and social metrics in their Life Cycle Analysis of logistics outsourcing. Interdependency can also be found in Azzone and Noci (1998), who suggest a performance measurement system where environmental measurements are linked to four different economic categories, namely: revenues, incremental contribution margin, internal efficiency costs and operation costs/investments. Ultimately the environmental measurements are linked to measures regarding the economic value creation of a company. Also Zhu et al. (2008) show examples of environmental measurements that are linked to economic performance.

Hervani et al. (2005) write that the performance management tool "the balanced scorecard" can be used when measuring environmental performance. Measures in the balanced scorecard belong to one of four perspectives, namely financial, customer, internal process and learning and growth. The authors give many examples of environmental measurements belonging to all four of these perspectives, e.g. disposal costs, green products, certified suppliers and percentage of renewable resource use. Cuthbertson and Piotrowicz (2008) have also written about the balanced scorecard and measurements. However, they try to fit measurements identified in their literature review into the four perspectives of the balanced scorecard. They only found environmental measurements in the organizational perspective (called internal process by Hervani et al. (2005)) and learning and growth perspectives.

The life cycle analysis is a measurement tool that aims at evaluating the environmental burden associated with a product, process or activity (Krikke et al., 2003). This tool only considers environmental issues but in reality economic and technical issues must also be taken into account.

\subsection{Conclusions from the literature review}

The literature review points to a need for more research in the field. Some of the shortcomings identified in the literature review are:

- There are increased environmental demands and pressures from a number of different stakeholders such as society, government, the market and industry. However, few of the articles describe how the results from measuring are communicated back to these stakeholders.

- There are different purposes to justify measurement at a general level, however few case descriptions present their purpose of measuring in a clear way and there is a large focus on measuring present effects of historical decisions instead of measuring to provide support for future management.

- There is a need to integrate the measures used on different managerial levels (strategic to operational). However, few present empirical examples of how this can be done.

- There is a need of measuring across the supply chain and to apply more process oriented measures. However few empirical examples are presented of how this can be done. 
These shortcomings have been taken into account in the selection, description and analysis of the case study in this article.

\section{THE CASE}

The supply chain studied is the Swedish reverse chain for used aluminum and plastic (PET) bottles for drinks. The Swedish system for returning these products differs compared to the systems applied in most other countries. It is based on collaboration between actors in the market: the retailers selling the drinks, wholesalers, breweries and the recycling company Returpack. Returpack is responsible for the reverse flows and the company is owned by the organizations of interest representing the retailers, wholesalers and breweries.

In 2007 Returpack became aware of the risks of future lack of capacity in the reverse system. Prognoses for year 2015 showed a large increase in volumes regarding both the number of used items and the shift from aluminum to the more voluminous PET bottles. This in turn resulted in too many packages in the inbound flow to Returpack's production unit for the sorting and compression of used bottles. Production planning is also challenging due to large variations in the inbound flow. The variations could be managed with increased storage, but there was not enough capacity for this in the system. Storage in itself is not a problem for this product due to its low value and the low demands on the storage (can for example be stored outside). Another problem identified was the large negative impact on the environment due to increased transport of used products.

The transport package used was identified as one important reason to not being able to handle the increased volumes as well as the increased use for transportation. Returpack saw economical and environmental potentials in applying a larger system perspective in designing a new reverse logistics system. In 2008 wholesalers and breweries shared the responsibility for the transport between the retailer and either the brewery or the wholesaler (i.e. the first transport link). Returpack was responsible for the transport from the wholesalers and breweries to Returpack's production unit, see figure 1. Each actor had optimized their flows and both wholesalers and breweries used what otherwise would be empty return transports after delivering goods to the retailers.

\section{Figure 1 here}

Possibilities to even the large variations in volumes, as well as change to a more environmental friendly transport mode, were identified if a larger system perspective was applied. In this case Returpack took responsibility for all transports. The first transport link in the new system can be described as a "milk round", collecting the used items from the retailers using a truck suitable for city transportation. This truck is less environmentally efficient than the much larger truck used in the second long distance transport link after storage. However, the city truck has equipment that makes it possible to compress the bottles and thereby reduce the transport volumes throughout the entire reverse flow.

Environmental and economical performance measurement was an important point of departure in designing the new reverse logistics system. The system in year 2008 was used as a comparison with four different scenarios, which are shown in figure 2 . In scenario 1 , the number of storages is 25 . To decrease the distances travelled with a less environmental efficient city truck the number of storages was increased to 40 in scenario 2.

In scenario 3 rail transports are used in the second transport link from four of the 40 storages (with longest distance). Scenario 4 represents maximum use of rail. In order to minimize the 
distance travelled with the city truck, the long distance truck is also used, resulting in three transport links.

\section{Figure 2 here}

Figure 3 shows the overall results from the environmental and economical performance measurement. The measurements applied in the assessment of the environmental and economical impact of the different scenarios in our case is in the next sections categorized using the framework presented in section 3.

Figure 3 here

\subsection{Stakeholder perspective}

The return flow is designed to meet the demands placed by Swedish authorities. Two laws from 2005 influence the operations. One law regards the need for a reverse system for metal cans and plastic bottles for consumer drinks. The other law regards the producers' responsibility and in accordance with this, $90 \%$ of the used bottles must be recycled. Furthermore, all actors in the reverse chain place demands on decreased costs for the entire reverse system and there is a constant effort to make the system more efficient.

\subsection{The purpose of measuring}

It was important to measure both the economical costs as well as the environmental impact from different types of scenarios when designing a new reverse system. Demands from the actors in the reverse chain regarding the costs of the system were one reason for economical measurements. One important reason for measuring the environmental impact was that wholesalers and breweries used empty return transports in 2008 and environmental arguments were placed from these two actors to keep the old system.

\subsection{Managerial levels of measuring}

The aim of the measurement and the development of possible scenarios were decided on a strategic level within Returpack. Due to the owning structure of Returpack this was also communicated and discussed with representatives at strategic managerial levels at wholesalers, breweries and retailers. The results from the measurements were communicated back to Returpack's board of management. Input to the environmental calculations was mainly gathered from the operative levels of all actors in the chain. Examples of such input regarded the routes driven by the different actors in order to gather the used products, including location of retailers, type of trucks applied, delivery frequencies, the volumes of returned products and cost for storage and handling.

\subsection{Measuring across the supply chain}

The performance measurement of the return flow from the retailer to Returpacks production unit included all four actors (Returpack, wholesalers, breweries and retailers).

By applying a larger system perspective, with four actors in the supply chain instead of only one, it is possible to reduce the risks of sub optimizations. Both the economic costs and the environmental impact from the first transport link from retailer to storage (at breweries and wholesalers in the system 2008) is much higher in all four scenarios, compared to the system 2008, see figure 4. The reason for this is that the wholesalers' and breweries' empty return transports are not used in the scenarios. On the other hand, the second transport link, from storage to Returpack, has less environmental impact in all scenarios compared to the system 
2008. As a result, the total environmental impact from transport is lower in the scenarios compared to 2008.

Figure 4 here

\subsection{Combination of measurements}

The focus in the environmental measurements was $\mathrm{CO}_{2}$ emissions. However, considerations were also taken to outlets of $\mathrm{NO}_{\mathrm{x}}, \mathrm{SO}_{2}, \mathrm{HC}, \mathrm{PM}$ and energy use (fossil, renewable and nuclear) from transportation. Other aspects such as transport mode selected, type of vehicle, vehicle $\mathrm{km}$ for each mode and transport volumes were also considered. The total logistics cost included costs for load carriers, costs for storage and handling for the retailers, warehouses, breweries, and transport costs for all transports.

In the design and development of the future reverse logistics system a balance has to be made between logistics costs and environmental impact. This balance act shows several win-win opportunities, but also an increase in costs in Scenario 3 and 4, since rail transports in these specific settings are more expensive than road transports. The future reverse logistics system will most likely be a combination of the four scenarios.

\section{DISCUSSION AND FURTHER RESEARCH NEEDS}

The low number of articles (17) identified in the area that combines measurement with environmental performance and logistics do indicate that this area is not well researched. Even if some of the articles presented a literature review, no paper presented a scope similar to the one of this study. During the literature study we have discovered shortcomings in all five dimensions covered in our framework. Four of these shortcomings are illustrated in figure 5 .

Figure 5 here.

First, there is a lack in consideration of the interest of different stakeholders. Even if the pressure from external stakeholders is described as one important reason for organisations to take environmental action, none of the articles describes how the results from the measuring are communicated back to these parties, besides that they publish external reports. It would be interesting to investigate if and to what extent the interest from these external stakeholders influence the design, execution and use of the performance measurement. In figure 5 the stakeholders are found externally, internally, as well as both upstream and downstream in the supply chain.

The second shortcoming has to do with the purpose of measuring, simply because the articles presenting examples of measurements seldom describe the purpose of the measuring. As a result a lot of different measurements are presented and the measurement systems become unnecessary complex. One paper (Gerbens-Leenes et al., 2003) does however describe a very narrow scope, which also facilitates a structural and result focused selection of a few but central measurements to use. The result is a measurement system that is easy to implement and use. This points to the need that researchers present clear and well limited purposes of their measurement study (number 2 in figure 5), instead of the too broad "measuring environmental supply chain management", in order to be able to provide more concrete advice and guidance to practitioners.

Thirdly, the literature study shows that previous research to a high extent is about the importance of including the strategic managerial level regarding environmental performance 
measurements. However, only a few articles provided concrete examples of doing so. One of these was the article by Cuthbertson and Piotrowicz (2008) that introduces measures on different managerial levels. Several of the articles also discuss the importance of linking the measures on different levels to each other, but none of the studied articles provide concrete examples of how this can be done. The shortcoming is represented by the number 3 in figure 5. Furthermore, we do question if it is the measurement in itself that is strategic, tactical or operational, or if it is the purpose of measuring and how the measurement results are used that decide whether they are strategic, operational or tactical.

When it comes to the measuring across the supply chain - number 4 in figure 5 - a shortcoming in the research is found here as well. Several of the articles studied discuss the importance of integrated measurement systems across the different actors and companies in the supply chain (e.g. Veleva et al., 2003; Hervani et al., 2005; Markley and Davis, 2007). However, the articles studied take a focal company perspective regarding in whose interest the measuring is made. Only one article has a different perspective than the focal company, and this is an article addressing the external costs of transportation from a societal point of view (Bickel et al., 2006). One interesting case for future research is to investigate how the measurements sometimes used in suppliers' business offerings are or can be designed and communicated to include the interest of buying companies.

Finally, several of the papers do point at the importance of connecting the environmental measurements to other areas of measurement, such as linking environmental performance to financial performance (e.g. Vasileiou and Morris, 2006; Azzone and Noci, 1998; Hervani et al., 2005). However, few of the articles do describe these links when presenting measurements.

The case we studied has succeeded in their use of environmental performance measurements. This case thereby shows that it is possible to succeed in environmental performance throughout a supply chain. They have overcome the lacks and shortcomings identified in the five dimensions of our framework. (1) The influence from stakeholders was an important driver to the specific measuring covered in this case description. The legal demands and demands from the actors in the reverse system place demands on a cost effective system. The environment was used as an argument not to change the system, which called for environmental measurements to investigate the potential environmental impact of a new system. (2) The purpose of measuring in the studied case was clear: to measure in order to provide support for the future design of the supply chain. This thereby also addresses the criticism from McIntyre and Smith (1998b) regarding the large focuses on historical measuring. (3) The support from the strategic managerial level is clear since they were the ones who identified the need for measuring. Operational personnel were involved in order to provide the necessary data for the measuring. The data was finally compiled in order to present an overall picture of the total environmental and economical result from the different scenarios to the strategic managerial level at all actors in the reverse chain. (4) Our case and the measurement system applied include four actors in a supply chain. Data availability is singled out as one reason why it is hard to measure environmental impact caused by a supply chain by Veleva et al. (2003). However, our case is unique since Returpack have access to most of the data needed since they need to keep track of the returned products and due to the unique owning situation. (5) Both environmental aspects and economical aspects are included in the measurement system, resulting in presenting scenarios where both these aspects are considered simultaneously, providing an ability to identify win-win situations between these two aspects.

The key success factor in the studied chain was the broad system approach where four supply chain actors were included. This eliminated the risk of sub optimization and enabled 
consideration of the total economical as well as environmental impact. The broader system also enabled changed roles among the actors in the studied chain.

The case also provides a good example of the benefits in the use of modeling and scenario studies as a way to guide management decisions. This shows the need for further research in the modeling of future scenarios and the use of the models to measure environmental impacts.

In this paper we have focused on examining one dimension of the framework at the time. There are likely to be several benefits and connections that can be found by considering several dimensions simultaneously. For example, are the measures on the strategic or operational managerial level within one company addressed on the same level also at the other companies in the supply chain? Are there measurements combined into the same measurement system at different managerial levels? There is a need for further research in order to answer these types of questions.

Furthermore, it is likely that the framework, or parts of the framework, can be applied into other areas than measuring, such as the spreading of knowledge and information, collaboration efforts and in the development of a business offering. This also calls for further research.

\section{ACKNOWLEDGEMENTS}

The authors wish to acknowledge and thank the case company Returpack Svenska AB for providing us with all empirical data. The authors also wish to thank VINNOVA for financially supporting the research project "Competitive business models to meet future demands on sustainable logistics systems" of which this article is a part.

\section{REFERENCES}

Aronsson, H., Huge Brodin, M. (2006), "The environmental impact of changing logistics structures", The International Journal of Logistics Management, Vol. 17 No. 3, pp. 394 - 415.

Azzone, G. and Noci, G. (1998), "Identifying effective PMSs for the deployment of "green" manufacturing strategies", International Journal of Operations \& Production Management, Vol. 18 Issue 4, pp. 308-335.

Bickel, P., Friedrich, R., Link, H., Stewart, L. and Nash, C., (2006), "Introducing Environmental Externalities into Transport Pricing: Measurement and Implications", Transport Reviews, Vol. 26 Issue 4, pp. 389-415.

Caplice, C. and Sheffi, Y. (1995), "A review and envaluation of logistics performance measurement systems", The international journal of logistics management, Vol. 6, No. 1, pp. 61-74.

Cuthbertson, R and Piotrowicz, W. (2008), "Supply chain best practices - identification and categorisation of measures and benefits" International Journal of Productivity \& Performance Management, Vol. 57 Issue 5, pp. 389-404.

Eisenhardt, K. M. (1989), "Building Theories from Case Study Research” Academy of Management Review, Vol. 14 Issue 4, p532-550.

Fabbe-Costes, N. and Jahre, M. (2008), "Supply chain integration and performance: a review of the evidence", International Journal of Logistics Management, Vol. 19 Issue 2, pp. 130154. 
Facanha, C. and Horvath, A. (2005), "Environmental Assessment of Logistics Outsourcing”, Journal of Management in Engineering, Vol. 21 Issue 1, p27-37.

Freight Best Practise (2009a), ”Monitoring and Understanding CO2 Emissions from Road Freight Operations", Available at: http://www.freightbestpractice.org.uk/performancemanagement. (accessed 9 March 2010).

Freight Best Practise (2009b), "Fleet Performance Management Tool Incorporating CO2 Emissions Calculator", Available at: http://www.freightbestpractice.org.uk/performancemanagement. (accessed 9 March 2010).

Gerbens-Leenes, P.W., Moll, H.C. and Schoot Uiterkamp, A.J.M. (2003) "Design and development of a measuring method for environmental sustainability in food production systems”, Ecological Economics, Vol. 46 Issue 2, pp. 231-248.

Gunasekaran, A., Patel, C. and McGaughey, R.E. (2004), A framework for supply chain performance measurement, International journal of production economics, Vol 87, pp. 333347.

Hervani, A. A., Helms, M. M and Sarkis, J. (2005), "Performance measurement for green supply chain management”, Benchmarking: An International Journal, Vol. 12 Issue 4, pp. 330-353.

Holmberg, S. (2000a), A system perspective on supply chain measurements, International journal of physical distribution \& logistics management, Vol 30, pp.847-868.

Holmberg, S., (2000b), Supply chain integration through performance measurements, $\mathrm{PhD}$ thesis, Lund University, Sweden.

Keller, S. B., Savitskie, K, Stank, T. P., Lynch, D. F. and Ellinger, A. E. (2002), “A summary and analysis of multi-item scales used in logistics research”, Journal of Business Logistics, Vol. 23 Issue 2, pp. 83-281.

Krikke, H., Bloemhof-Ruwaard, J. and Van Wassenhove, L. N. (2003), “Concurrent product and closed-loop supply chain design with an application to refrigerators", International Journal of Production Research, Vol. 41 Issue 16, pp. 3689-3719.

Lakhal, S. Y. and H'Mida, S. (2007), "Green supply chain parameters for a Canadian petroleum refinery company", International Journal of Environmental Technology \& Management, Vol. 7 Issue 1/2, p56-67

Lu, L. Y.Y., Wu, C.H. and Kuo, T.-C. (2007), "Environmental principles applicable to green supplier evaluation by using multi-objective decision analysis", International Journal of Production Research, Vol. 45 Issue 18/19, pp. 4317-4331.

Markley, M. J. and Davis, L. (2007), "Exploring future competitive advantage through sustainable supply chains”, International Journal of Physical Distribution \& Logistics Management, Vol. 39 Issue 9, pp. 763-774.

McIntyre, K., Smith, H. A., Henham, A. and Pretlove, J. (1998a), "Environmental performance indicators for integrated supply chains: the case of Xerox Ltd”, Supply Chain Management: An International Journal, Vol 3 Issue 3, pp. 149-156.

McIntyre, K., Smith, H. A., Henham, A. and Pretlove, J. (1998b), "Logistics Performance Measurement and Greening Supply Chains: Diverging Mindsets", International Journal of Logistics Management, Vol. 9 Issue 1, p57-68.

McKinnon, A. C. (2003), “Logistics and the environment”, Hensher, D. A. and Button, K. J. (ed.), Handbook of transport and the environment, Elsevier, Amsterdam, pp. 665-685. 
Neely, A. (1998), Measuring Business Performance, The Economist Books, London, UK.

Noci, G. (1995), “Accounting and non accounting measures of quality based performance in small firms”, International journal of operations \& production management, Vol. 15 No. 7, pp. 78-105.

Seuring, S. A. (2008) "Assessing the rigor of case study research in supply chain management”, Supply Chain Management: An International Journal, Vol. 13 Issue 2, p128137.

Vachon, S. and Klassen, R. D. (2008), “Environmental management and manufacturing performance: The role of collaboration in the supply chain”, International Journal of Production Economics, Vol. 111 Issue 2, pp. 299-315.

Vanteddu, G., Chinnam, R. B. and Yang, K. (2006), “A performance comparison tool for supply chain management”, International journal of logistics systems and management, Vol. 2, No. 4 pp. 342-356.

Vasileiou, K. and Morris J. (2006), “The sustainability of the supply chain for fresh potatoes in Britain”, Supply Chain Management, Vol. 11 Issue 4, pp. 317-327.

Veleva, V., Hart, M., Greiner, T. and Crumbley, C. (2003), "Indicators for measuring environmental sustainability: A case study of the pharmaceutical industry", Benchmarking: An International Journal, Vol. 10 Issue 2, pp. 107-119.

Yin, R. K. (2003), Case study research: design and methods, Thousand Oaks: Sage

Zsidisin, G. A. and Sifert, S. P. (2001), "Environmental purchasing: A framework for theory development”, European Journal of Purchasing and Supply Management, Vol. 7, no 1.

Zhu, Q., Sarkis, J. and Lai, K. (2008), "Confirmation of a measurement model for green supply chain management practices implementation” International Journal of Production Economics, Vol. 111 Issue 2, pp. 261-273. 
Figure 2 Transportation in the four scenarious

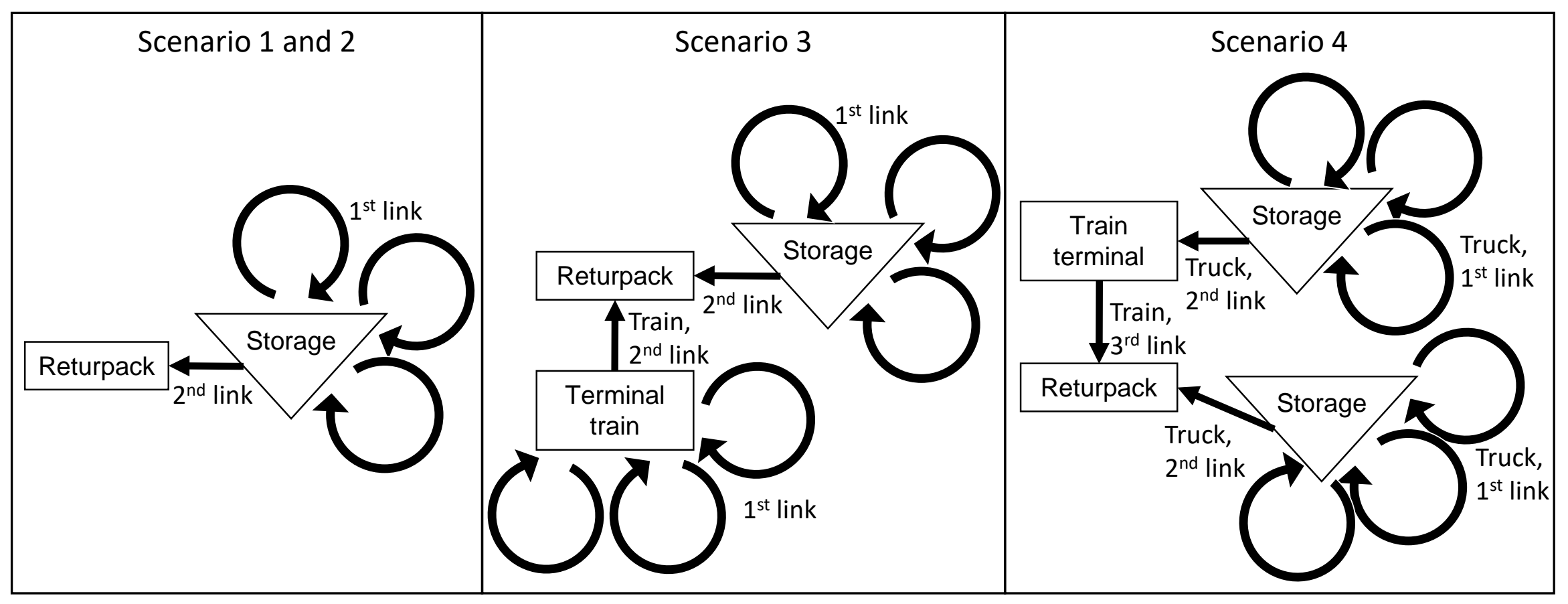


Figure 3 Environmental impact and total costs in the scenarios.

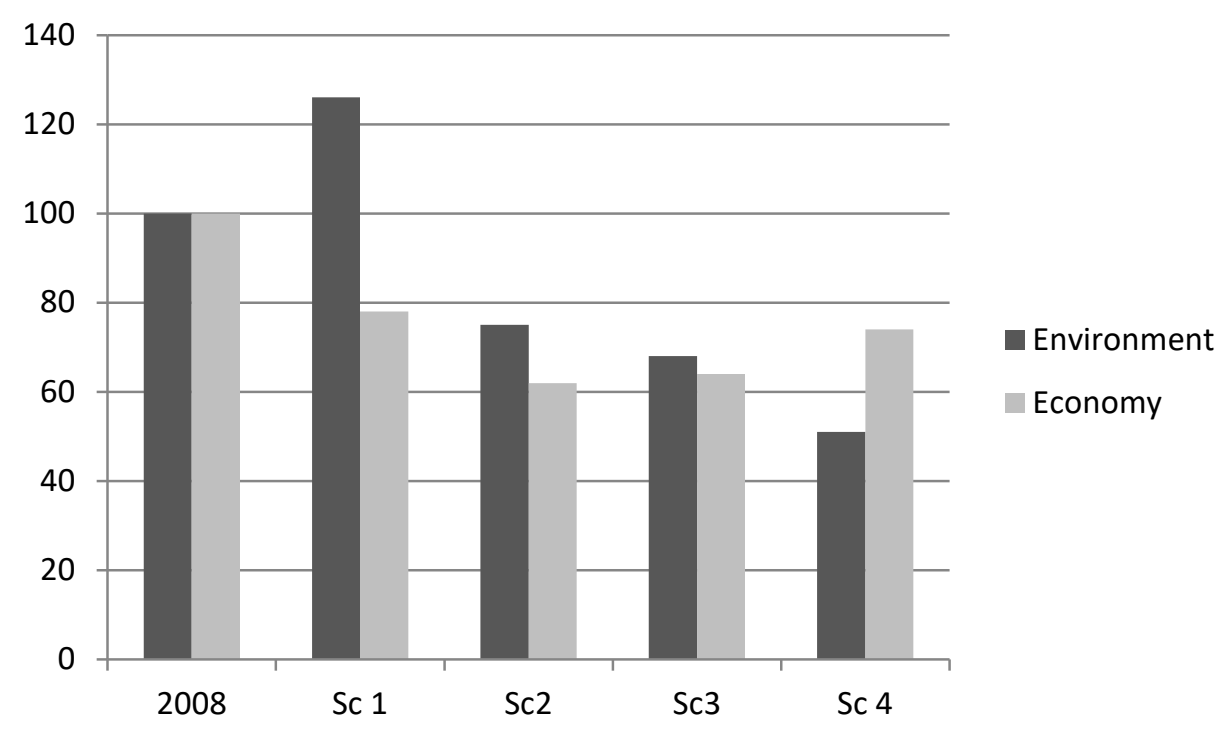

Clarifications: The system 2008 is used as a baseline (100\%). Environmental performance is based on $\mathrm{CO}_{2}$ emissions and the economic performance on the costs for transport, storage, packages and handling. 
Figure 4 Transport costs and environmental impact (CO2) in the two transport links.

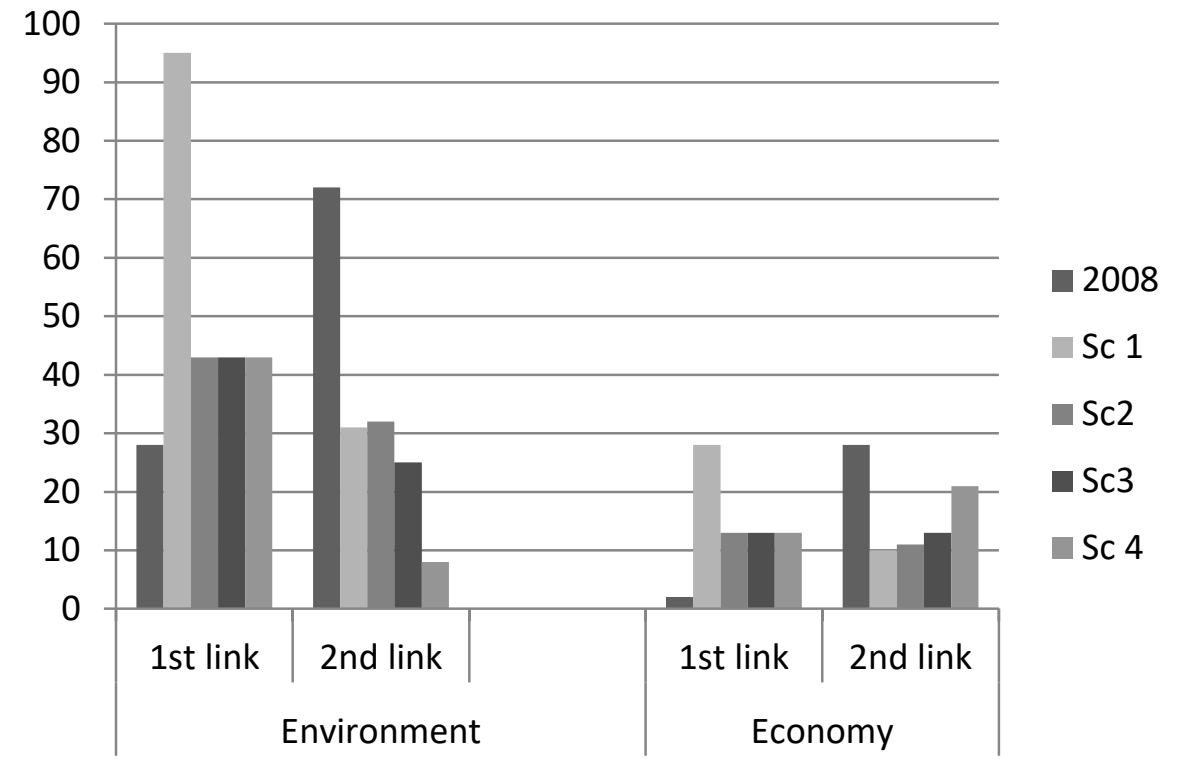

Clarifications: See Figure 2, 3, 4 and 5 for clarification regarding the $1^{\text {st }}$ and $2^{\text {nd }}$ transport link. 
Figure 5. Gaps in environmental logistics measurement research.

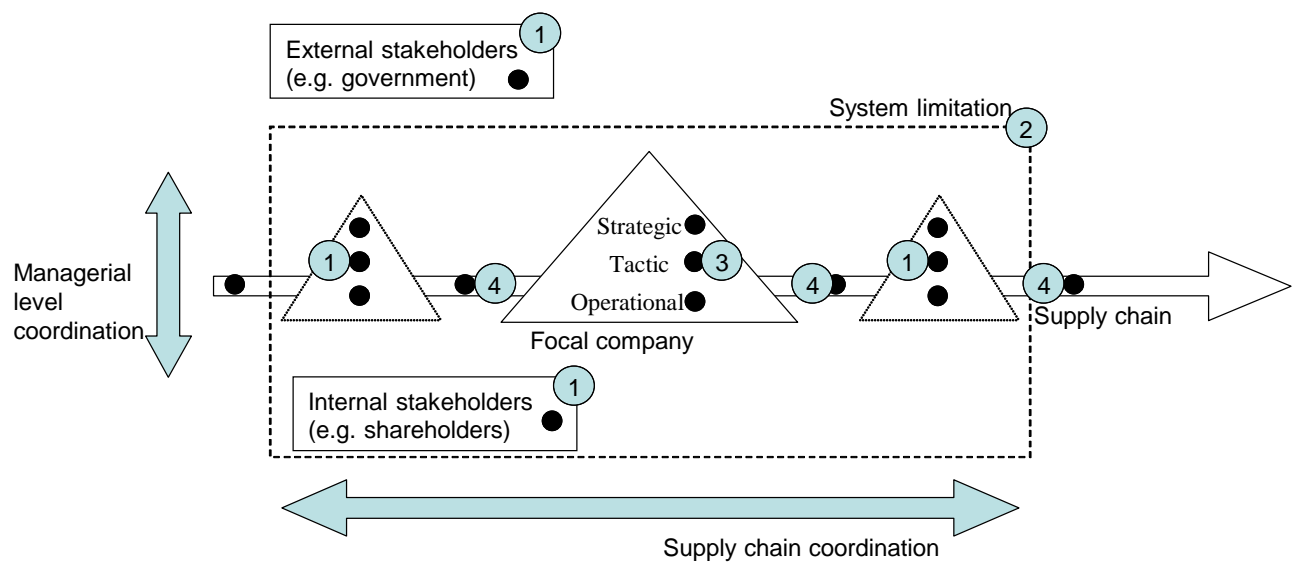

Gaps/Lack identified in the field:

1. Lack in consideration of the interest of different stakeholders

2. Lack in defining the purpose and thereby narrow down the“system" measured.

3. Lack of coordination between different managerial levels.

4. Lack of coordination across the supply chain. 